\title{
EFFECT OF USE OF BONE-MARROW CENTRIFUGATE ON MUSCLE INJURY TREATMENT: EXPERIMENTAL STUDY ON RABBITS
}

Daniel Ferreira Fernandes Vieira' ${ }^{1}$, Roberto Guarniero ${ }^{2}$, Carlos Eduardo Sanches Vaz ${ }^{3}$, Paulo José de Santana ${ }^{4}$

\section{ABSTRACT}

Objective: The objective of this study was to evaluate the effect of bone-marrow centrifugate on the healing of muscle injuries in rabbits. Methods: This experimental study involved use of fifteen adult male New Zealand White rabbits. Each animal received a transverse lesion in the middle of the right tibialis anterior muscle, to which an absorbable collagen sponge, soaked in a centrifugate of bone marrow aspirate from the ipsilateral iliac bone, was added. The left hind limb was used as a control and underwent the same injury, but in this case only the absorbable collagen sponge. Thirty days later, the animals were sacrificed to study the muscle healing. These muscle areas were subjected to histological analysis with histomorphometry, with the aim of measuring the number of muscle cells per square micrometer undergoing regeneration and the proportion of resultant fibrosis. Results: The centrifugation method used in this study resulted in an average concentration of nucleated cells greater than the number of these cells in original aspirates, without causing significant cell destruction. Addition of the bone marrow centrifugate did not result in any significant increase in the number of muscle cells undergoing regeneration, in relation to the control group. There was also no significant difference in the proportion of resultant fibrosis, compared with the control group. Conclusion: Administration of the bone marrow centrifugate used in this study did not favor healing of muscle injuries in rabbits.

Keywords - Bone Marrow; Stem Cells; Regeneration; Skeletal Muscle; Animals Models; Rabbits

\section{INTRODUCTION}

Muscle injuries constitute one of the most challenging problems of sports traumatology, since although common, their treatment is still controversial, and often inefficient ${ }^{(1)}$. Long periods of leave of absence are habitually necessary for athletes to fully resume their activities and sequelae can be part of the end result ${ }^{(2)}$.

The muscle tissue healing process usually starts promptly as soon as a trauma occurs; however, it can evolve slowly and irregularly, hindered by an excessive formation of connective scar tissue (fibrosis) ${ }^{(3)}$.
This scar tissue in excess inhibits the complete regeneration of the preexisting muscle structure, and, as it is more fragile and anomalous, contributes towards the local recurrence of the lesion, preventing the complete recovery of muscle function ${ }^{(4)}$.

The treatment employed most often in muscle injuries is conservative, involving measures such as rest, immobilization of the affected limb for a variable time, local application of ice and physiotherapeutic monitoring. In some cases, depending on the severity of the lesion, its surgical repair may be indicated. Although these treatments frequently lead to good clinical results, they appear to have a limited effect

\footnotetext{
1 - Orthopedics and Traumatology, Master's degree in Medicine and Health Sciences at the Universidade Estadual de Londrina - Londrina, PR, Brazil.

2 - Associate Professor of the School of Medicine of Universidade de São Paulo - São Paulo, SP, Brazil.

3 - Doctor and Adjunct Professor of the Orthopedics and Traumatology Discipline of Universidade Estadual de Londrina - Londrina, PR, Brazil.

4 - Doctor and Adjunct Professor of the Orthopedics and Traumatology Discipline of Universidade Estadual de Londrina - Londrina, PR, Brazil.

Study conducted at the LIM 41 - Laboratory of Medical Investigation of the Musculoskeletal System of the Department of Orthopedics and Traumatology of the School of Medicine of Universidade de São Paulo and in the Orthopedics and Traumatology Discipline of Universidade Estadual de Londrina.

Mailing address: Carlos Eduardo Sanches Vaz, Rua Borba Gato, 1.078, ap. 1.202, Jardim das Américas - 86010-630 - Londrina, PR. Email: carlos.vaz@sercomtel.com.br Study received for publication: 11/30/2010, accepted for publication: $05 / 26 / 2011$..
} 
on functional recovery and the risk of recurrence ${ }^{(2)}$.

The limitations described gave rise to surveys investigating biological measures capable of stimulating the muscle regeneration process and of preventing fibrosis formation ${ }^{(5)}$. This resulted in a better identification of the cellular and molecular pathways involved in muscle regeneration and in a more complete understanding of the activity of satellite cells and pluripotent cells, capable of myogenic differentiation during muscle healing ${ }^{(6,7)}$. This better understanding of the muscle repair process made room for favorable prospects in the appearance of new therapies ${ }^{(8)}$.

Tissue repair, replacement and regeneration techniques, employing tissue engineering knowledge have recently achieved promising results, which include the capturing and transplantation of precursor cells and the use of bioactive matrices, peptide hormones and growth factors ${ }^{(9)}$.

Among these new techniques, two lines of research have been studied extensively: 1) the local application of platelet-rich plasma, due to its supposed healing properties, attributed to the ability to recruit, proliferate and differentiate cells involved in tissue repair; and 2) therapies based on the direct local addition of embryonic stem cell cultures, in the hope that the latter will differentiate in the cells of the target tissue.

Although therapies based on the local addition of embryonic stem cell cultures produced in vitro have demonstrated the ability to differentiate into muscle cells (myocytes) ${ }^{(10,11)}$, the culturing and the transplantation of undifferentiated bone marrow cells are complex, costly procedures with technology restricted to large research centers ${ }^{(12)}$. Consequently, the local application of bone marrow aspirates containing adult stem cells has been researched clinically and experimentally ${ }^{(13)}$. The latter have limited tissue differentiation potential in comparison to embryonic stem cells, yet they are able to produce bone, cartilaginous and muscle cells ${ }^{(14)}$. Since the local addition of myocytes is related to an increase of muscle regeneration at the lesion site, the local application of a sufficient number of their precursor cells constitutes a promising approach in the attempt to improve muscle healing ${ }^{(15,16)}$.
The aim of this study was to evaluate the positive effect of the addition of bone-marrow centrifugate in the healing of muscle injuries in rabbits.

\section{METHODS}

This experimental study was evaluated and approved, on March 13, 2007, by the Animal Research Ethics Committee of Universidade Estadual de Londrina.

The study subjects were 15 adult male New Zealand White (Orytolagus cuniculus) rabbits with mean weight of $3 \mathrm{~kg}$ and approximate age of four months, from the Experimental Farm of Iguatemi, of Universidade Estadual de Maringá, and bred in the Vivarium of the Health Sciences Center, of Universidade Estadual de Londrina. As there is no consensus in literature regarding the appropriate method for calculating the size of the ideal sample for the study in question, we opted to use a number of animals similar to that used in the reference studies. Moreover, the current ethical guidelines for animal research recommend the use of the lowest possible number of animals, as long as they provide significant statistical results. The animals were evaluated previously by a veterinarian and were accommodated in individual metal cages, with 12 continuous hours of daily light, and with room temperature, humidity and noise kept stable. Their diet consisted of water ad libitum and appropriate balanced and pelleted industrial feed.

\section{Preparation of the bone marrow centrifugate}

The anesthetic procedure was based on the anesthesia protocol advocated by the Canadian Council on Animal Care, in the Guide to the Care and Uses of Experimental Animals ${ }^{(17)}$. One $\mathrm{mg} / \mathrm{kg}$ of atropine sulfate was applied in each animal by intramuscular route as a preanesthetic medication. The anesthesia started with the intramuscular application, in the proximal region of the pelvic limb, of a solution containing $40 \mathrm{mg} / \mathrm{kg}$ of $10 \%$ ketamine chlorhydrate, associated with $5 \mathrm{mg} / \mathrm{kg}$ of xylazine chlorhydrate. Soon after the anesthesia induction, the animals were identified with numbers ranging from 1 to 15 , tattooed in the left ear. The fractionated administration of $1 \mathrm{mg} / \mathrm{kg}$ xylazine chlorhydrate was performed when it was necessary to prolong the anesthesia. 
The skin of the right iliac crest region was trichotomized, and after appropriate asepsis and antisepsis, the surgeon performed the puncture of the bone marrow from the posterior iliac crest, using a $16 \mathrm{G}$ needle with trocar. The medullary cavity was reached with delicate rotation movements. After this, the trocar was removed, connecting to the needle a $10 \mathrm{ml}$ disposable plastic syringe, the inside of which had been previously soaked in a heparin solution at 1:1.000. Approximately $5 \mathrm{ml}$ of bone marrow were aspirated with firm traction of the syringe piston.

The material was processed in a laminar flow chamber under sterile conditions. To disperse the cellular aggregates, the $5 \mathrm{ml}$ sample from the plastic syringe was transferred to a sterile graduated tube, initially through a 19 gauge needle, then using a 22 gauge needle. The material was centrifuged at $400 \mathrm{G}$ and at $20^{\circ} \mathrm{C}$, for 10 minutes. After centrifugation, the aspirate split into three distinct levels: an upper layer containing the blood plasma, an intermediate layer known as the buffy-coat, where we can find the nucleated cells (due to their greater density), which include hematopoietic precursor cells and marrow stromal cells, the site where it is possible to find the mesenchymal and progenitor cells (bone, cartilaginous and muscle cell precursors). Finally, the last layer is composed of the red cells sedimented at the bottom of the tube. The buffy-coat material was then homogenized, and a sample of 50 microliters was separated to count the cells and to carry out a cell viability test, to avoid the administration of dead cells that could result from the centrifugation process.

\section{Surgical technique}

The anesthetized animal was positioned in dorsal decubitus on the operating table, performing trichotomy of the anterior surfaces of the right and left legs, and appropriate asepsis and antisepsis.

A longitudinal, anteromedial access route was made in the middle third of the hind limb, approximately $3 \mathrm{~cm}$ in length. This was followed by dissection by planes, approaching skin, subcutaneous tissue and fascia, which were pulled aside, exposing the body of the tibialis anterior muscle. Using a no. 15 scalpel blade, a crosswise incision was made in the body of the tibialis anterior muscle, covering $75 \%$ of its width, $50 \%$ of its thickness and approxi- mately $60 \%$ of its length, starting from its proximal origin, according to the model of Menetrey et $a l^{(18)}$. This is done to avoid the total crosswise section of the muscular venter, enabling more uniform healing between the muscle portions separated by the incision and sparing the motor nerve at its point of penetration in the muscle ${ }^{(6)}$.

After this, the surgeon placed proximal and distal repair stitches at a distance of $5 \mathrm{~mm}$ from the edges of the muscle injury, using 4.0 mononylon suture thread, according to the procedure recommended by Marlow et $a l^{(19)}$. A sample of absorbable gelatin sponge $\left(\right.$ Gelfoam $\left.^{\circledR}\right)$ measuring $1.0 \times 0.5 \mathrm{~cm}$ was soaked in the bone marrow centrifugate and placed over the lesion (Figure 1).

The surgical wound was sutured by planes using 4.0 mononylon suture thread and occluded with a sterile impermeable dressing. The same procedure was carried out in the left tibialis anterior muscle;

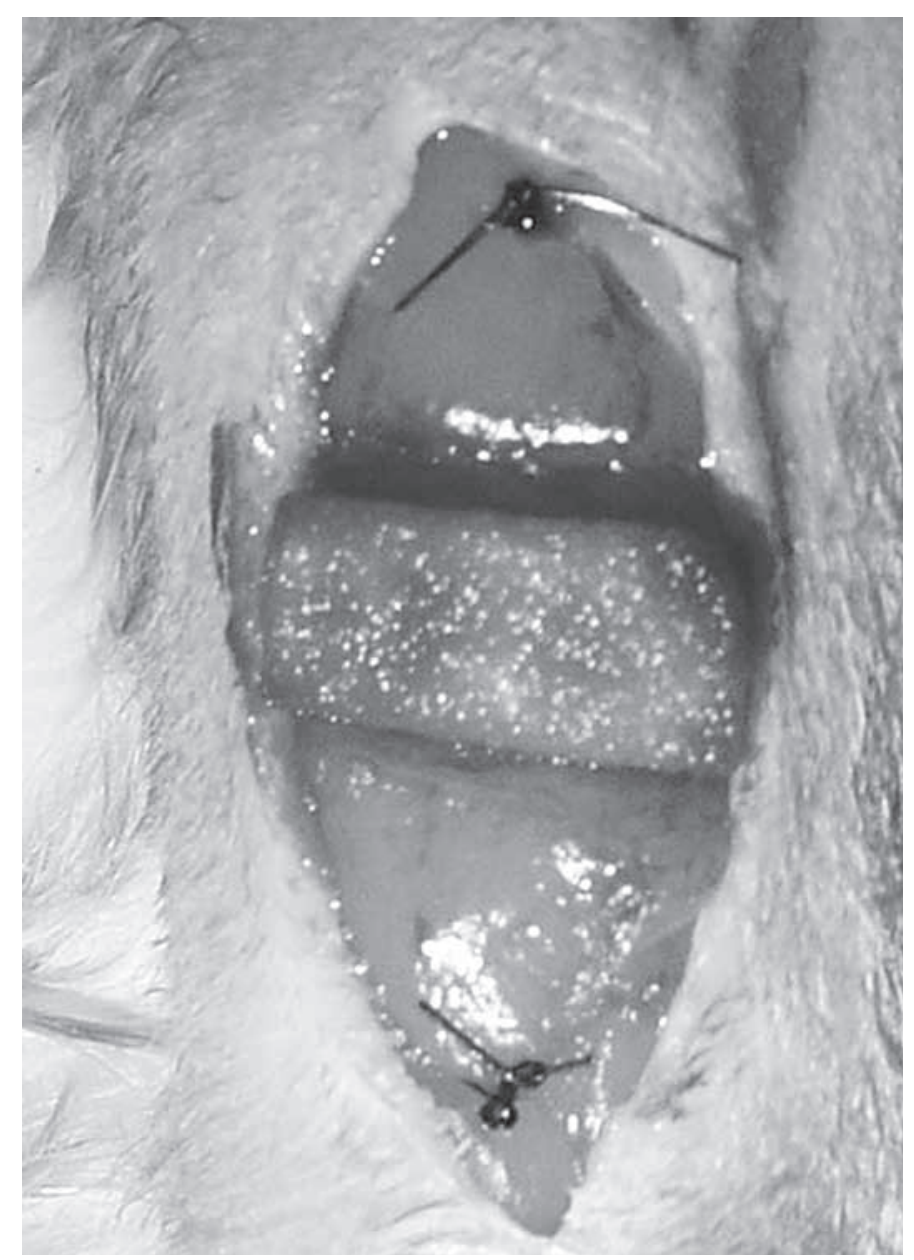

Figure 1 - Muscle repair and absorbable gelatin sponge soaked in bone marrow centrifugate on the lesion of the right tibialis anterior muscle. 
yet only the absorbable gelatin sponge was applied at the site.

At the end of surgery, the animal was isolated from the other animals, placed in an appropriate box and heated. An intramuscular dose of antibacterial and anti-inflammatory drug containing penicillin $\mathrm{G}$ benzathine, penicillin $\mathrm{G}$ procaine, dihydrostreptomycin sulfate and piroxicam was administered. After total recovery from anesthesia, the rabbit was returned to its cage, receiving water and feed ad libitum. Full weight-bearing on the operated limbs was authorized and allowed immediately, without any type of restriction or immobilization. According to Järvinen et $a l^{(1)}$, early mobilization induces faster and more intense capillary growth into the injured area, better regeneration and more parallel muscle fiber orientation, while inactivity is associated with significant atrophy of the muscle fibers and excessive fibrosis deposition.

Thirty days after the surgery date, the animals were sacrificed. The right and left tibialis anterior muscles of each animal were carefully dissected from their proximal to their distal insertion and removed. The proximal and distal surgical repair stitches were located, $5 \mathrm{~mm}$ from the lesion site, and the muscle was sectioned between these stitches, according to the experimental model described by Menetrey et $a l^{(18)}$.

After this, the proximal and distal halves of the muscles were placed in appropriate containers, fixed in a $10 \%$ formalin solution, and identified with the rabbit's number and corresponding hind limb (right or left).

The muscle tissue samples were then dehydrated and soaked in paraffin for the histological study, positioned in such a way that the location of the surface of the middle line would allow cross sections from the middle point of the injury. Histological sections with a thickness of $4 \mu \mathrm{m}$ were obtained from the paraffin blocks, and followed the histological routine for staining with hematoxylin-eosin, for histopathological and histomorphometric evaluation.

The evaluation of results was performed by the quantitative histological measurement (number of muscle cells per $\mu \mathrm{m}^{2}$ and proportion of fibrosis) of healing of the muscle injury, comparing the right tibialis anterior muscle with the left from the surface of the middle line of their segments, in the intermediate region of the muscle injury, which is the ideal region for quantification of muscle regeneration, as it occurs regardless of vascular supply and in an environment not influenced by fibrous repair, reflecting only the myogenic potential.

The findings were then documented in scanned images captured with the assistance of the Kontron Electronic 300 (Zeiss ${ }^{\circledR}$ ) image analysis system, for the quantitative evaluation. This semi-automated routine was carried out in each field of the slide under analysis, with 10 fields per slide. The results obtained in each field, corresponding to the analyzed area (number of muscle cells per $\mu \mathrm{m}^{2}$ and proportion of fibrosis), were filed in a Microsoft Excel ${ }^{\circledR}$ spreadsheet for subsequent statistical analysis.

The statistical analysis was performed in the Department of Statistics of the Center of Exact Sciences of Universidade Estadual de Londrina.

The mean, the standard deviation, the median and the interquartile amplitude of the continuous quantitative variables were all measured.

Statistical tables and column charts (mean \pm standard deviation) presented the descriptive statistics of the variables: number of muscle cells $/ \mu \mathrm{m}^{2}$ and proportion of fibrosis.

Wilcoxon's test was used for inference on the difference between the observations of the paired and nonparametric samples.

The significance level adopted was $5 \%(\alpha=0.05)$.

\section{RESULTS}

Table 1 contains the results of the cell count and of the cell viability test, carried out after the bone marrow aspirate centrifugation.

Table 2 and Figure 2 demonstrate the number of muscle cells per square micrometer formed at the site of the muscle injury, treated with bone marrow centrifugate, in comparison to the control group.

Table 3 and Figure 3 demonstrate the percentage of fibrosis formed at the site of the muscle injury, treated with bone marrow centrifugate, in comparison to the control group.

\section{DISCUSSION}

Muscle injuries are extremely common, constituting around $35-55 \%$ of all sports-related injuries. The associated morbidity is significant since these injuries can lead to painful muscle contractures and atrophies, 
Table 1 - Descriptive statistics of the nucleated cell count in each sample of bone marrow aspirate and determination of their cell viability.

\begin{tabular}{|c|c|c|c|c|c|c|c|c|c|c|c|}
\hline \multirow{3}{*}{ Rabbit } & \multirow{3}{*}{$\begin{array}{l}\text { Puncture } \\
\text { volume } \\
\text { (ml) }\end{array}$} & \multirow{3}{*}{$\begin{array}{c}\text { Mean count } \\
(107 \text { cells } / \\
\mathrm{ml})\end{array}$} & \multicolumn{9}{|c|}{ Nucleated cell } \\
\hline & & & \multicolumn{3}{|c|}{ Viable } & \multicolumn{5}{|c|}{ Non-viable } & \multirow{2}{*}{$\begin{array}{c}\begin{array}{c}\text { Cell viability } \\
(\%)\end{array} \\
97.0\end{array}$} \\
\hline & & & $1 \mathrm{st}$ & 2nd & $M$ & 1st & 2nd & M & & M & \\
\hline 1 & 5.0 & 10.2 & 97 & 100 & 99 & 2 & 4 & 3 & $\#$ & 3 & 97.0 \\
\hline 2 & 5.0 & 3.4 & 32 & 34 & 33 & 1 & 1 & 1 & \# & 1 & 97.9 \\
\hline 3 & 4.0 & 4.9 & 51 & 44 & 48 & 1 & 1 & 1 & \# & 1 & 95.6 \\
\hline 4 & 5.0 & 4.6 & 40 & 47 & 44 & 1 & 2 & 2 & \# & 2 & 97.4 \\
\hline 5 & 3.0 & 7.8 & 73 & 78 & 76 & 1 & 3 & 2 & \# & 2 & 95.5 \\
\hline 6 & 3.0 & 6.7 & 65 & 62 & 64 & 3 & 3 & 3 & \# & 3 & 96.0 \\
\hline 7 & 5.0 & 5.0 & 53 & 43 & 48 & 3 & 1 & 2 & \# & 2 & 90.6 \\
\hline 8 & 6.0 & 7.5 & 66 & 69 & 68 & 6 & 8 & 7 & \# & 7 & 96.8 \\
\hline 9 & 7.0 & 9.5 & 94 & 90 & 92 & 2 & 4 & 3 & \# & 3 & 96.3 \\
\hline 10 & 4.5 & 13.6 & 130 & 132 & 131 & 4 & 5 & 5 & \# & 5 & 94.9 \\
\hline 11 & 5.5 & 5.9 & 56 & 55 & 56 & 2 & 4 & 3 & \# & 3 & 92.5 \\
\hline 12 & 6.0 & 8.1 & 78 & 71 & 75 & 6 & 5 & 6 & \# & 6 & 93.6 \\
\hline 13 & 5.0 & 4.7 & 47 & 40 & 44 & 3 & 3 & 3 & \# & 3 & 94.9 \\
\hline 14 & 5.5 & 7.9 & 72 & 77 & 75 & 2 & 6 & 4 & \# & 4 & 92.5 \\
\hline 15 & 5.5 & 4.0 & 31 & 42 & 37 & 2 & 4 & 3 & $\#$ & 3 & \\
\hline
\end{tabular}

1st - First count -2 nd - Second count $-M-$ Mean count

Table 2 - Descriptive statistics of the number of muscle cells formed at the site of the muscle injury, comparing the side where the bone marrow centrifugate was applied with the control side.

\begin{tabular}{|c|c|c|}
\hline \multirow{2}{*}{ Rabbit } & \multicolumn{2}{|c|}{ Number of muscle cells $/ \mu \mathrm{m}^{2}$} \\
\hline & $\begin{array}{c}\text { Bone marrow } \\
\text { centrifugate (BMC) }\end{array}$ & Control (C) \\
\hline 1 & 0.000202916 & 0.000202135 \\
\hline 2 & 0.000754903 & 0.000339927 \\
\hline 3 & 0.000522031 & 0.000297436 \\
\hline 4 & 0.000156089 & 0.000417183 \\
\hline 5 & 0.000364207 & 0.000569724 \\
\hline 6 & 0.000376955 & 0.000339927 \\
\hline 7 & 0.000587284 & 0.000400628 \\
\hline 8 & 0.000366809 & 0.000348273 \\
\hline 9 & 0.000422149 & 0.000417183 \\
\hline 10 & 0.000304373 & 0.000207598 \\
\hline 11 & 0.000476781 & 0.000147504 \\
\hline 12 & 0.000242805 & 0.000182104 \\
\hline 13 & 0.000327787 & 0.000195111 \\
\hline 14 & 0.000143407 & 0.000176034 \\
\hline 15 & 0.000392351 & 0.000196672 \\
\hline $\begin{array}{l}\text { Mean } \pm \text { standard } \\
\text { deviation }\end{array}$ & $0.000376 \pm 0.0001647$ & $0.000296 \pm 0.0001219$ \\
\hline Difference (BMC-C) & $0.000080 \pm 0.0001796$ & \\
\hline $\begin{array}{c}\text { Median (interquartile } \\
\text { amplitude) }\end{array}$ & $0.000367(0.0002340)$ & $0.000297(0.0002055)$ \\
\hline Difference (BMC-C) & $0.000061(0.0001949)$ & \\
\hline Wilcoxon & $S=32$ & $p=0.0730$ \\
\hline
\end{tabular}

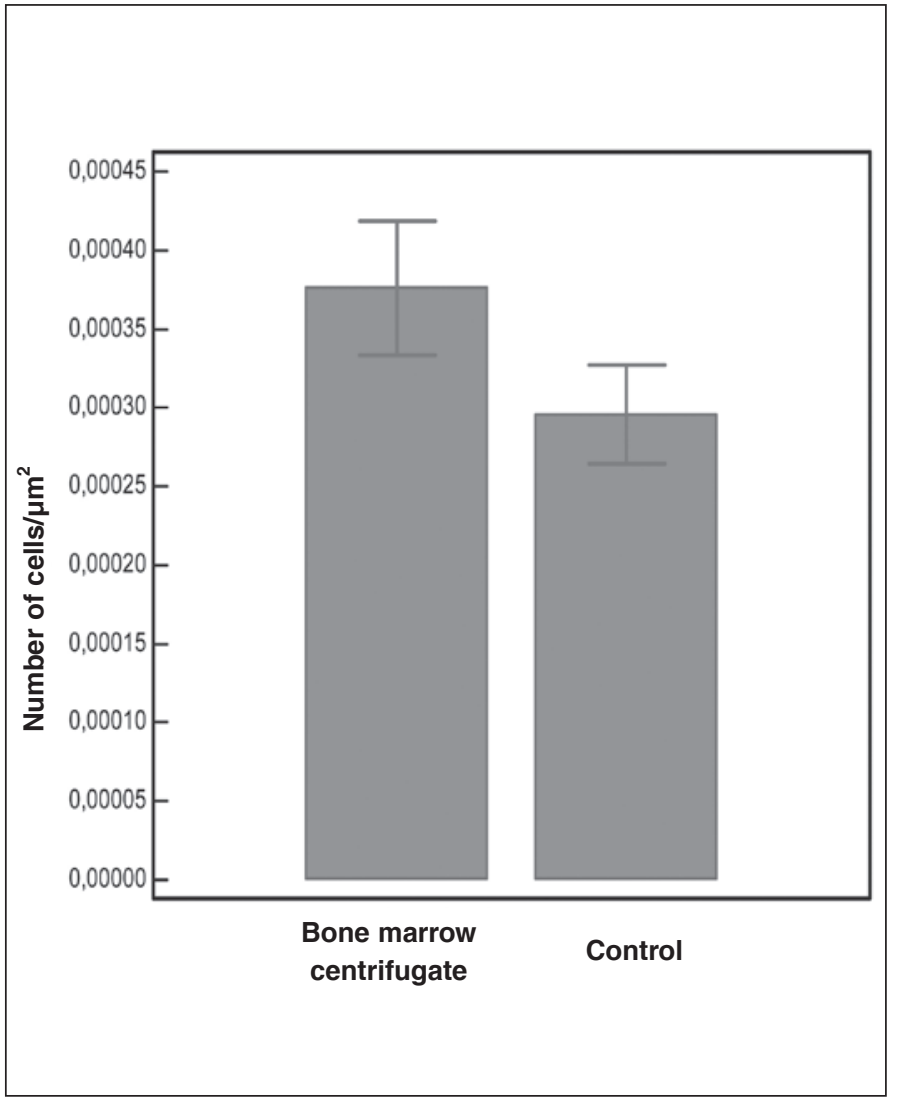

Figure 2 - Number of muscle cells by square micrometer in the intermediate region of the injury of the tibialis anterior muscle treated with bone marrow centrifugate and control. 
Table 3 - Comparative descriptive statistics of the percentage of fibrosis formed at the muscle injury sites.

\begin{tabular}{|c|c|c|}
\hline \multirow[b]{2}{*}{ Rabbit } & \multicolumn{2}{|c|}{ Proportion of fibrosis } \\
\hline & $\begin{array}{c}\text { Bone marrow } \\
\text { centrifugate (BMC) }\end{array}$ & Control (C) \\
\hline 1 & 0.601304503 & 0.469212643 \\
\hline 2 & 0.525683356 & 0.642372385 \\
\hline 3 & 0.361749355 & 0.445195018 \\
\hline 4 & 0.666412294 & 0.377530994 \\
\hline 5 & 0.676205576 & 0.593659394 \\
\hline 6 & 0.343374895 & 0.699801392 \\
\hline 7 & 0.555734885 & 0.500963831 \\
\hline 8 & 0.500546007 & 0.583348253 \\
\hline 9 & 0.387811732 & 0.379854791 \\
\hline 10 & 0.567422834 & 0.491287125 \\
\hline 11 & 0.646452016 & 0.37336342 \\
\hline 12 & 0.663838047 & 0.543644596 \\
\hline 13 & 0.630006334 & 0.513283371 \\
\hline 14 & 0.302357471 & 0.672787984 \\
\hline 15 & 0.59545864 & 0.448178945 \\
\hline $\begin{array}{l}\text { Mean } \pm \text { standard } \\
\text { deviation }\end{array}$ & $0.534957 \pm 0.12778$ & $0.515632 \pm 0.10568$ \\
\hline Difference (BMC-C) & $0.019325 \pm 0.19402$ & \\
\hline $\begin{array}{c}\text { Median (interquartile } \\
\text { amplitude) }\end{array}$ & $0.567423(0.25864)$ & $0.500964(0.14846)$ \\
\hline Difference (BMC-C) & $0.076136(0.21554)$ & \\
\hline Wilcoxon & $S=13$ & $p=0.4887$ \\
\hline
\end{tabular}

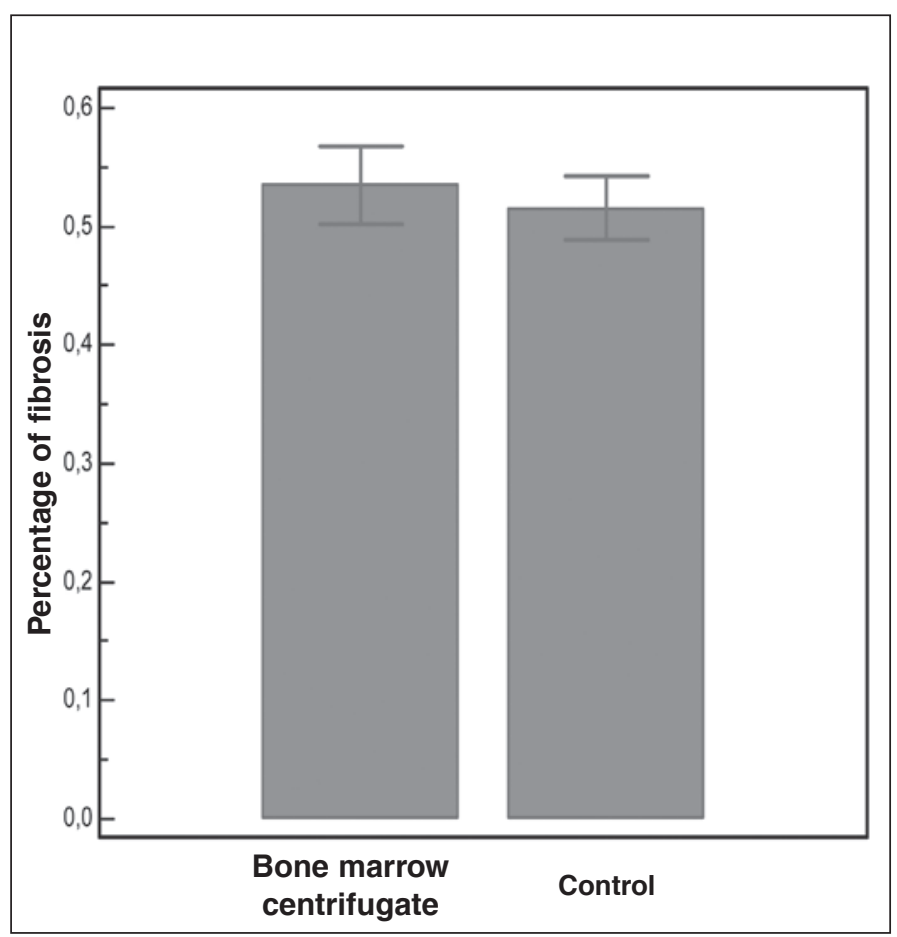

Figure 3 - Proportion of fibrosis in the intermediate region of the injury of the tibialis anterior muscle treated with bone marrow centrifugate and control. require long periods of recovery, increase the risk of recurrence and, in some cases, make it difficult for athletes to return to their pre-injury activity level.

In recent years, the development of cell and tissue engineering therapies has stimulated research employing these techniques in the treatment of muscle injuries. The purpose of these therapies is to stimulate an increase in the formation of muscle cells in the affected region, and, at the same time, to reduce the formation of excess connective scar tissue (fibrosis). The latter is directly related to the rate of recurrent injuries and has been shown capable of preventing athletes from returning to their pre-injury state, partly as it prevents the formation of new myofibrils, contributing towards the decline of muscle contractility and of range of motion ${ }^{(20)}$. The pain resulting from the formation of fibrosis is also a limiting factor for total functional recovery during physiotherapy and in the long-term.

Although studies evidence the ability of embryonic progenitor cell (embryonic stem cell) cultures to form bone, cartilaginous and muscle tissues, this technology is expensive and complex, and, therefore, still far from the daily clinical practice. Because of this, the initiative of our using in our survey aspirates from bone marrow, which demonstrably contains, in its stroma, adult mesenchymal tissue precursor cells. These cells also present the potential, although more limited than the embryonic precursory cells, to differentiate into muscle cells.

We use the muscle injury model described by $\mathrm{Me}-$ netrey et $a l^{(18)}$, which impedes the total separation of the muscle fibers, favoring the study of healing. On the lesion site, we apply absorbable collagen foam, soaked in the bone marrow centrifugate, to prevent the dispersion of the cells and to allow their more prolonged contact with the lesion, since the foam remains at the site for approximately fifteen days before being absorbed completely. The samples of bone marrow aspirate were centrifuged with the objective of separating the nucleated cells, of which both hematopoietic precursor cells and stromal cells form part. After the centrifugation process is complete, these cells are concentrated in the intermediate layer of the tubes (buffy-coat).

Although the model used does not faithfully reproduce the muscle injuries most frequently encountered 
in the clinical practice, which are those caused by contusion or laceration mechanism, we opted for the model proposed by the cited authors as it allows a better standardization of the injury in each animal. According to these authors, this model is easy to execute and eliminates variables such as extension, depth and intensity of the force applied when attempting to cause the injury by contusion or laceration, allowing a better characterization of the muscle healing.

Another conflicting factor in our study was the option to sacrifice the animals with a single time interval of four weeks. Ideally, we should evaluate the healing in several periods, which would allow a more uniform and linear follow-up. However, this would require a much larger sample group of animals, which has been discouraged by animal protection societies and animal welfare boards. Nowadays they advocate the use of the lowest possible quantity of animals, and uphold that people should preferably work at tissue level (histology). Moreover, there is no standardization, in literature, of the calculation of the most appropriate number of animals for this type of study.

In spite of all these precautions, our results demonstrated that there was no significant difference in the number of muscle cells formed at the site of the muscle lesions where the bone marrow centrifugate was applied, in comparison with the control side. Neither was there any difference in the percentage of fibrosis formed, which allows us to conclude that the bone marrow concentrate was not able to improve the quality of the muscle scar.

Although literature frequently refers to mesenchymal progenitor cells of the bone marrow as a homogeneous population, these cells are actually very heterogeneous, differing greatly in their ability to differentiate into adult muscle cells. Therefore, even when the same technique is employed for their obtainment, bone marrow aspirates can be very different in relation to the quantity of truly precursor cells present in each collected sample. This may be one of the causes of failure in our study. According to Matziolis et $a l^{(21)}$, the inflammatory process triggered by a muscle injury can lead to the death of the myogenic precursor cells implanted immediately, which may result in cell survival below $10 \%$ on the fifth day after the trauma. This is apparently caused by the cellular and humoral factors that form part of the physiological inflammation processes during the first days after the injury. Moreover, the damage to microvascularization results in poor regenerative response in this phase. Together, these factors create a hostile environment that hinders the survival, the proliferation and the differentiation of transplanted cells, contributing to justify the negative results found in our study.

Although tissue regeneration mediated by embryonic stem cells in vitro has promising therapeutic potential, Musarò et $a l^{(10)}$ believe that the differentiation in the skeletal muscle of adult stem cells originating from the bone marrow has hardly any clinical import.

In this study, the greater proportion of fibrosis in the treatment group, although not significant, came as a surprise, demonstrating that the excessive formation of connective scar tissue, in the opinion of other authors, is a problem yet to be resolved.

The results obtained in this study demonstrate that the bone marrow centrifugate was not able to induce a better quality of muscle healing, increasing the number of muscle fibers and reducing fibrosis formation.

One alterative that has been the focus of recent surveys seeking to repair and/or to regenerate the muscle tissue is the use of platelet concentrate, also known as platelet-rich plasma (PRP) ${ }^{(22)}$.

The platelets are the first cells to reach the site of the injury and are very active in the initial inflammatory phase of tissue repair. They act in tissue homeostasis, by means of adherence, aggregation, formation of clots and release of substances (growth factors) that promote tissue repair and that influence local neovascularization ${ }^{(23)}$.

Platelets release growth factors through degranulation, and the interest in their local application at lesion sites is due precisely to the possibility of enhancing tissue healing potential through the direct administration of these factors. These factors are concentrated by means of techniques of centrifugation of autologous blood from the actual patient, producing a platelet-rich substance that can be applied in liquid or gelatinous form on the injured tissue ${ }^{(23)}$. 
In spite of its considerable appeal, recent studies have demonstrated that there is still a great deal of controversy regarding the true efficacy of PRP, mainly due to the non-standardization of variables such as quantity to be applied, concentration, time interval etc. Most surveys appear to demonstrate a favorable effect in the treatment of chronic tendinosis, but conflicting results in bone and muscle application ${ }^{(24)}$.

Further studies should be conducted, perhaps using homogeneous populations of mesenchymal progenitor cells, in an attempt to regenerate the muscle fibers, resulting in more adequate muscle healing and in the complete recovery of pre-injury muscle function.

\section{CONCLUSION}

The administration of the bone marrow centrifugate used in this study did not favor the healing of muscle injuries in rabbits.

\section{REFERENCES}

1. Järvinen $T A$, Järvinen $T L$, Kääriäinen $M$, Kalimo $H$, Järvinen $M$. Muscle injuries:biology and treatment. Am J Sports Med. 2005;33(5):745-64.

2. Armfield DR, Kim DH, Towers JD, Bradley JP, Robertson DD. Sports-related muscle injury in the lower extremity. Clin Sports Med. 2006;25(4):803-42.

3. Buckwalter JA, Cruess RL. A cura dos tecidos musculoesqueléticos. In: Rockwood CA, Green DP, Bucholz RW, editores. Fraturas em adultos. 3a. ed.. São Paulo: Manole; 1993. p. 179-219.

4. Garrett WE Jr, Seaber AV, Boswick J, Urbaniak JR, Goldner JL. Recovery of skeletal muscle after laceration and repair. J Hand Surg Am. 1984;9(5):683-92.

5. Huard J, Li Y, Fu FH. Muscle injuries and repair: current trends in research. J Bone Joint Surg Am. 2002;84 A(5):822-32.

6. Chargé SB, Rudnicki MA. Cellular and molecular regulation of muscle regeneration. Physiol Rev. 2004;84(1):209-38.

7. Shefer G, Wleklinski-Lee M, Yablonka-Reuveni Z. Skeletal muscle satellite cells can spontaneously enter an alternative mesenchymal pathway. J Cell Sci. 2004;117(Pt 22):5393-404.

8. Griffith LG, Naughton G. Tissue engineering--current challenges and expanding opportunities. Science. 2002;295(5557):1009-14.

9. Muschler GF, Nakamoto C, Griffith LG. Engineering principles of clinical cellbased tissue engineering. J Bone Joint Surg Am. 2004;86(7):1541-58.

10. Musarò A, Giacinti C, Borsellino G, Dobrowolny G, Pelosi L, Cairns L, et al. Stem cell-mediated muscle regeneration is enhanced by local isoform of insulinlike growth factor 1. Proc Natl Acad Sci U S A. 2004;101(5):1206-10.

11. Fukada S, Miyagoe-Suzuki Y, Tsukihara H, Yuasa K, Higuchi S, Ono S, et al. Muscle regeneration by reconstitution with bone marrow or fetal liver cells from green fluorescent protein-gene transgenic mice. J Cell Sci. 2002;115(Pt 6):1285-93

12. Vaz CES. Avaliação do efeito de centrifugado osteogênico de medula óssea na consolidação de fratura: estudo experimental em coelhos [tese]. São Paulo: Universidade de São Paulo; 2006.
13. Connolly JF. Injectable bone marrow preparations to stimulate osteogenic repair. Clin Orthop Relat Res. 1995;(313):8-18.

14. Bianco P, Riminucci M, Gronthos S, Robey PG. Bone marrow stromal stem cells: nature, biology, and potential applications. Stem Cells. 2001;19(3):180-92.

15. Ferrari G, Cusella-De Angelis G, Coletta M, Paolucci E, Stornaiuolo A, Cossu $\mathrm{G}$, et al. Muscle regeneration by bone marrow-derived myogenic progenitors. Science. 1998;279(5356):1528-30.

16. Muschler GF, Midura RJ. Connective tissue progenitors: practical concepts for clinical applications. Clin Orthop Relat Res. 2002;(395):66-80.

17. Olfert ED, Cross BM, McWilliam AA. editors. (1993). Guide to the Care and Use of Experimental Animals. 2nd ed. Ottawa: Canadian Council on Animal Care; 1993.

18. Menetrey J, Kasemkijwattana C, Fu FH, Moreland MS, Huard J. Suturing versus immobilization of a muscle laceration. A morphological and functional study in a mouse model. Am J Sports Med. 1999;27(2):222-9.

19. Marlow SA, McGeachie JK, Tennant M, Papadimitriou JM. A morphometric technique for the histological quantification of skeletal muscle regeneration. $J$ Anat. 1996;189 ( Pt 1):151-8.

20. Kääriäinen $M$, Järvinen $T$, Järvinen $M$, Rantanen J, Kalimo H. Relation between myofibers and connective tissue during muscle injury repair. Scand J Med Sci Sports. 2000 Dec;10(6):332-7. Review. PubMed PMID: 11085560

21. Matziolis G, Winkler T, Schaser K, Wiemann M, Krocker D, Tuischer J, Perka C,Duda GN. Autologous bone marrow-derived cells enhance muscle strength following skeletal muscle crush injury in rats. Tissue Eng. 2006;12(2):361-7.

22. Cole BJ, Seroyer ST, Filardo G, Bajaj S, Fortier LA. Platelet-Rich Plasma:Where are we now and where are we going?. Sports Health. 2010;2:203-10.

23. Foster TE, Puskas BL, Mandelbaum BR, Gerhardt MB, Rodeo SA. Plateletrich plasma: from basic science to clinical applications. Am J Sports Med. 2009;37(11):2259-72.

24. Hall MP, Band PA, Meislin RJ, Jazrawi LM, Cardone DA. Platelet-rich plasma: current concepts and application in sports medicine. J Am Acad Orthop Surg. 2009;17(10):602-8. 